\title{
Article Suicide-Related Knowledge and Attitudes among a Sample of
Mental Health Professionals
}

 \\ David Lester $\left.{ }^{4}{ }^{(}\right)$, Marco Innamorati ${ }^{5}{ }^{-}$and Maurizio Pompili $1, *(\mathbb{C})$
}

1 Department of Neurosciences, Mental Health and Sensory Organs, Faculty of Medicine and Psychology, Suicide Prevention Centre, Sant'Andrea Hospital, Sapienza University of Rome, 00100 Rome, Italy; denise.erbuto@gmail.com (D.E.); isabella.berardelli@uniroma1.it (I.B.); alice.sparagna@hotmail.it (A.S.); gaianigrelli@yahoo.it (G.N.)

2 Department of Human Neuroscience, Sapienza University of Rome, 00100 Rome, Italy; salvatore.sarubbi@uniroma1.it

3 Department of Psychology, Sapienza University of Rome, 00100 Rome, Italy; elena.rogante@uniroma1.it

4 Psychology Program, Stockton University, Galloway, NJ 08205, USA; david.lester@stockton.edu

5 Department of Human Sciences, European University of Rome, 00100 Rome, Italy; marco.innamorati@unier.it

* Correspondence: maurizio.pompili@uniroma1.it

+ These authors have contributed equally to this work.

Citation: Erbuto, D.; Berardelli, I.; Sarubbi, S.; Rogante, E.; Sparagna, A.; Nigrelli, G.; Lester, D.; Innamorati,

M.; Pompili, M. Suicide-Related

Knowledge and Attitudes among a Sample of Mental Health

Professionals. Int. J. Environ. Res.

Public Health 2021, 18, 8296. https://

doi.org/10.3390/ijerph18168296

Academic Editor: Daniel Pratt

Received: 10 June 2021

Accepted: 30 July 2021

Published: 5 August 2021

Publisher's Note: MDPI stays neutral with regard to jurisdictional claims in published maps and institutional affiliations.

Copyright: () 2021 by the authors. Licensee MDPI, Basel, Switzerland. This article is an open access article distributed under the terms and conditions of the Creative Commons Attribution (CC BY) license (https:// creativecommons.org/licenses/by/ $4.0 /)$.

\begin{abstract}
Inadequate knowledge of the potential signs and risk factors of suicide negatively affects the ability of healthcare professionals to recognize patients at risk of suicide. The principal aim of the present study is to assess the attitudes and knowledge about suicide in a large sample of mental health professionals. We examined the relationship between Suicide Knowledge and Skills Questionnaire items and the experience of a patient dying by suicide. We also examined whether various healthcare professionals respond differently to the items of the Impact of a Patient's Suicide on Professional and Personal Lives Scale. Results demonstrated that healthcare professionals who had experienced a patient suicide reported greater skills than professionals who had not experienced a patient suicide. However, $44 \%$ of professionals who had experienced a patient suicide felt that they did not have adequate training on this particular issue. Among those who had experienced a patient suicide, there was an increased tendency to hospitalize patients with suicide risk and an increased use of collegial consultation. Concerning personal emotions, healthcare professionals reported troubled relationships with family members and friends and the loss of self-esteem. In conclusion, better knowledge and attitudes about suicide are necessary for suicide-prevention strategies.
\end{abstract}

Keywords: suicide; knowledge; attitudes; prevention

\section{Introduction}

The knowledge of how to identify and manage suicidal patients is important in suicide prevention. Training a range of professionals, not exclusively healthcare professionals, is an essential strategy in suicide prevention [1,2], and evidence suggests that training is necessary to increase knowledge about suicide in healthcare professionals [3-6]. Several studies have highlighted the fact that only half of the mental health trainees had received very limited training on suicide during their education [7]. Workshops proved to be effective for improving knowledge and shifting attitudes [8], although appropriate training, without supervised practice, does not necessarily imply that professionals obtain essential skills to deal with suicidal patients [9]. Moreover, patients at risk of suicide often visit primary care services rather than mental health professionals, thereby conferring an important role for primary care physicians for suicide assessment and prevention [10]. It has been reported that contact with primary healthcare services was highest in the year before suicide, with an average contact rate of $80 \%$, while at one month the average rate was $44 \%$ [11]. Inadequate knowledge of the potential signs and risk factors of suicide 
negatively affects the ability of healthcare professionals to recognize patients at risk of suicide $[12,13]$. Improved knowledge and attitudes about suicide may allow healthcare professionals to better identify patients at risk, increasing suicide-prevention efforts. We define attitudes as a set of emotions, beliefs, and behaviors toward a particular object, person, thing, or event $[14,15]$.

A patient's suicide is not a rare event for healthcare professionals. At least half of all psychiatrists may have a patient who dies by suicide, and most professionals with previous experience can expect another suicide [16]. A patient's suicide usually has a significant impact on healthcare professionals, affecting them on both a professional and a personal level [17]. The suicide of a patient can increase awareness of the various factors involved in suicide risk, creating anxiety, guilt, and high levels of stress [16]. Moreover, healthcare professionals often display negative attitudes toward patients with suicidal behaviors [18]. On the other hand, a patient's suicide can offer an opportunity for professional growth, providing insight on personal competencies and encouraging consultations [19]. Regardless, healthcare professionals could benefit from improved knowledge about suicide, and training in suicide prevention may be necessary.

Based on the hypothesis that the attitudes of healthcare professionals toward people who died by suicide and their knowledge about suicide risk influence suicide-prevention strategies [20,21], the principal aim of the present study is to assess knowledge and attitudes about suicide in a large sample of mental health professionals. For this purpose, we examined the relation between Suicide Knowledge and Skills Questionnaire items [22] and the experience of a patient's suicide. In addition, we also examined whether various healthcare professionals (i.e., physicians, psychologists, nurses) respond differently to the items of the Impact of a Patient's Suicide on Professional and Personal Lives Scale.

\section{Materials and Methods}

\subsection{Participants}

A total of 670 healthcare professionals (physicians, psychologists, nurses, and educators) and medical and psychology students participated in the study (Table 1). Out of the 670 participants, 511 were female and the average was 44.89 years $(S D=13.81)$. Subjects were recruited during the 16th International Symposium on Suicidology and Public Health, which occurred in Rome in 2018. Approximately $26.7 \%$ of participants were physicians, $32.8 \%$ were psychologists, $14.2 \%$ were nurses, $15.7 \%$ were students, $4.3 \%$ were educators, and $5 \%$ were other mental health professionals (Table 1). Participants were invited to complete the questionnaire based on their skills and knowledge about suicide and the impact of a patient suicide on their lives. Approximately 250 healthcare professionals did not participate in the study Participation was voluntary and anonymous, and researchers and those associated with the project did not know the participants' identities. Therefore, the information collected did not contain any identifiable information, and there was no risk of attributing data to particular individuals. All participants received a comprehensive explanation of the study procedures and goals, consistent with Helsinki's Declaration. The project was submitted to the university department (Department of Neurosciences, Mental Health and Sensory Organs), which provided approval. 
Table 1. Characteristics of the sample.

\begin{tabular}{|c|c|}
\hline Participants & Percentage $(\%)$ \\
\hline \multicolumn{2}{|l|}{ Sex } \\
\hline Male & 23.6 \\
\hline Female & 76.3 \\
\hline Age-M \pm SD (years) & $44.89 \pm 13.81$ \\
\hline \multicolumn{2}{|l|}{ Profession } \\
\hline Physician & 26.7 \\
\hline Child neuropsychiatry & 3.0 \\
\hline Psychiatry & 17.8 \\
\hline Neurology & 0.6 \\
\hline Psychotherapy & 7.3 \\
\hline Other specialties & 1.5 \\
\hline Psychologist & 32.8 \\
\hline Nurse & 14.2 \\
\hline Educator & 4.3 \\
\hline Resident & 1.3 \\
\hline Student & 15.7 \\
\hline Other & 3.7 \\
\hline \multicolumn{2}{|l|}{ Job affiliation } \\
\hline Outpatient clinic & 40.0 \\
\hline Inpatient clinic & 12.3 \\
\hline Other & 26.0 \\
\hline Unknown & 21.7 \\
\hline Profession-number of years- $-\mathrm{M} \pm \mathrm{SD}$ & $19.78 \pm 11.50$ \\
\hline Past experiences of patients' suicide & 37.31 \\
\hline Number of suicides experienced by the professional (mean) & 2.21 \\
\hline
\end{tabular}

\subsection{Measures}

We administered a socio-anamnestic questionnaire to all participants that included data on age, gender, and profession. The questionnaire also included a section reserved for professionals who had experienced a patient suicide.

The Suicide Knowledge and Skills Questionnaire (SKSQ) [22] is a 13-item questionnaire to assess knowledge about suicidal behaviors and perceived competence in managing suicidal patients. The questionnaire includes two scales: the suicide knowledge subscale with nine true or false sentences and the suicide skills subscale that estimates how confident healthcare professionals are in their training, skills, and supervision when managing suicidal patients. Responses are on a 5-point Likert scale that ranges from completely agree to disagree completely. Previous studies [22,23] only reported statistics on internal consistency and did not evaluate further the psychometric properties of the SKSQ. Both Smith et al. [22] and Silva et al. [23] reported low internal consistency for the suicide knowledge subscale (Cronbach's alpha between 0.40 and 0.50), and acceptable internal consistency for the suicide skills confidence subscale (Cronbach's alpha between 0.81 and 0.84); the low internal consistency of the suicide knowledge subscale was associated with the miscellaneous nature of the items [22,23]. Supporting the validity of the SKSQ as a measure of suicide-related knowledge and perceived skills, results from Smith et al. [22] suggest that scores on both subscales are able to discriminate between health professionals with specific training in suicide prevention and those who do not have any training. In the present sample, Cronbach's alphas were 0.44 for the suicide knowledge subscale and 0.84 for the suicide skills confidence subscale. However, we did not treat the SKSQ as a 
psychometric scale (e.g., we did not calculate and interpret total scores as an index of a latent construct), and we analyzed only single items.

A self-report scale to assess the impact of a patient's suicide on healthcare professionals' professional and personal lives [24] was administered only to professionals who had experienced a patient suicide. This scale included 18 items that focused on personal life (e.g., personal feelings and difficulties with family members and friends) and professional life (e.g., changes in clinical practice and relationships with colleagues and supervisors). Responses were on a 7-point Likert scale with $1=$ minimum impact and $7=$ maximum impact. The authors $[24,25]$ did not develop the items as part of a psychometric scale but used them only as part of a survey and did not perform any analysis to study the validity or reliability of the questionnaire. In the present sample, Cronbach's alpha was 0.89 . In line with the original studies $[24,25]$, we did not use total scores and analyzed only responses to single items.

To analyze the results, we converted the 5-point Likert scale responses to the suicide skills subscale and the 7-point Likert scale responses to the Impact of a Patient's Suicide on Professional and Personal Lives Scale to a 3-point response range. In the first questionnaire, we merged the responses "strongly disagree" and "disagree" and the responses "agree" and "strongly agree", while in the second questionnaire we considered responses from 1 to 3 as "disagree", responses from 5 to 7 as "agree", and response 4 as "neither". Since the distribution of the scores was non-normal, non-parametric statistics were used.

\section{Results}

Descriptive statistics are shown in Table 1. On average, participants had performed their job for 19.78 ( \pm 11.50$)$ years. Over a third of the participants $(37.31 \%)$ had experienced the suicide of a patient during their career.

Examining the relationship between items of the suicide skills subscale and experience of patient suicide, those who had never experienced a patient suicide were less confident about their training and skills for handling suicidal patients (see Table 2). They were less likely to agree with the statements: "I have received the training I need to engage and assist those with suicidal desire", "I have the skills I need to engage those with suicidal desire and /or intent", and "I am comfortable asking direct and open questions about suicide". However, a large percentage of those who had experienced a patient's suicide felt that they did not have enough training or skills: $44.3 \%$ did not believe they had received the necessary training to engage and assist those with suicidal desire, $25.1 \%$ were not confident about their skills to engage patients with suicidal ideation, and $18.9 \%$ were not comfortable asking about suicide (Table 2). To study whether participants' years of professional experience could affect the relationship between the experience of patients' suicide and the participants' suicide skills, we performed a loglinear analysis with the experience of a patients' suicide as a dependent variable and variables significant at the bivariate analyses (i.e., training, skills, and comfort) and years of experience as independent variables. The model fitted the data adequately (Likelihood Ratio $\chi^{2}=0.93, p=0.63$ ). The experience of a patient's suicide was significantly associated with comfort in asking about suicide (Odds Ratio $=2.19, p=0.001$ ). In contrast, having enough training (Odds Ratio $=1.26$, $p=0.49$ ) or skills (Odds Ratio $=1.38, p=0.31$ ), and years of experience (Odds Ratio $=1.02$, $p=0.73$ ) were not significantly associated with the experience of a patients' suicide. What is noteworthy here is, regardless of the experience of a patient suicide, a large proportion of the participants did not feel that they had the training or skills to help suicidal patients, and $60 \%$ of the total sample did not feel that they had the support and supervision that they needed to engage with and assist those with suicidal desires.

There were no significant associations between knowledge about suicide and the experience of a patient suicide (see Table 3 ). 
Table 2. Contingency table suicide skills subscale items: past experiences of patients' suicide.

\begin{tabular}{|c|c|c|c|c|c|c|c|}
\hline \multirow[t]{2}{*}{ Suicide Skills Subscale Items } & & \multicolumn{2}{|c|}{$\begin{array}{c}\text { No Patient } \\
\text { Suicide Reported }\end{array}$} & \multicolumn{2}{|c|}{$\begin{array}{l}\text { Past Patient } \\
\text { Suicide }\end{array}$} & \multirow[b]{2}{*}{$x^{2}$} & \multirow[b]{2}{*}{$p$} \\
\hline & & $N$ & $\%$ & $N$ & $\%$ & & \\
\hline \multirow{3}{*}{$\begin{array}{c}\text { I have received the TRAINING } \\
\text { I need to engage and assist those with suicidal } \\
\text { desire }\end{array}$} & Disagree & 210 & 62.9 & 104 & 44.3 & \multirow{3}{*}{23.02} & \multirow{3}{*}{$<0.001$} \\
\hline & Undecided & 55 & 16.5 & 43 & 18.3 & & \\
\hline & Agree & 69 & 20.7 & 88 & 37.4 & & \\
\hline \multirow{3}{*}{$\begin{array}{l}\text { I have the SKILLS } \\
\text { I need to engage those with suicidal desire } \\
\text { and/or intent }\end{array}$} & Disagree & 179 & 53.1 & 59 & 25.1 & \multirow{3}{*}{53.26} & \multirow{3}{*}{$<0.001$} \\
\hline & Undecided & 85 & 25.2 & 67 & 28.5 & & \\
\hline & Agree & 73 & 21.7 & 109 & 46.4 & & \\
\hline \multirow{3}{*}{$\begin{array}{l}\text { I am comfortable asking direct and open } \\
\text { questions about suicide }\end{array}$} & Disagree & 153 & 45.4 & 45 & 18.9 & \multirow{3}{*}{55.28} & \multirow{3}{*}{$<0.001$} \\
\hline & Undecided & 58 & 17.2 & 32 & 13.4 & & \\
\hline & Agree & 126 & 37.4 & 161 & 67.6 & & \\
\hline \multirow{3}{*}{$\begin{array}{c}\text { I have the SUPPORT/SUPERVISION } \\
\text { I need to engage and assist those with suicidal } \\
\text { desire }\end{array}$} & Disagree & 209 & 62.0 & 133 & 56.7 & \multirow{3}{*}{1.86} & \multirow{3}{*}{0.39} \\
\hline & Undecided & 37 & 11.0 & 32 & 13.6 & & \\
\hline & Agree & 91 & 27.0 & 70 & 29.8 & & \\
\hline
\end{tabular}

Table 3. Suicide knowledge by experience with a suicide.

\begin{tabular}{|c|c|c|c|c|c|c|c|}
\hline \multicolumn{2}{|c|}{ Items of Suicide Knowledge Questionnaire } & \multicolumn{2}{|c|}{$\begin{array}{c}\text { No Patient Suicide } \\
\text { Reported }\end{array}$} & \multicolumn{2}{|c|}{$\begin{array}{l}\text { Past Patient } \\
\text { Suicide }\end{array}$} & \multirow[b]{2}{*}{$x^{2}$} & \multirow[b]{2}{*}{$p$} \\
\hline & & $N$ & $\%$ & $N$ & $\%$ & & \\
\hline \multirow[t]{2}{*}{ 1. Few people want to kill themselves $(\mathrm{F})$} & $\begin{array}{c}\text { UNCORRECT } \\
\text { RESPONSE }\end{array}$ & 116 & 34.0 & 102 & 40.8 & \multirow[t]{2}{*}{2.85} & \multirow[t]{2}{*}{0.09} \\
\hline & CORRECT RESPONSE & 225 & 66.0 & 148 & 59.2 & & \\
\hline \multirow{2}{*}{$\begin{array}{l}\text { 2. Youth ages } 10-24 \text { have a significantly } \\
\text { greater risk of suicide than individuals } \\
\text { aged } 65 \text { or older }(\mathrm{F})\end{array}$} & $\begin{array}{l}\text { UNCORRECT } \\
\text { RESPONSE }\end{array}$ & 209 & 61.3 & 142 & 56.8 & \multirow{2}{*}{1.21} & \multirow{2}{*}{0.27} \\
\hline & CORRECT RESPONSE & 132 & 38.7 & 108 & 43.2 & & \\
\hline \multirow{2}{*}{$\begin{array}{l}\text { 3. The rate of suicide among those with } \\
\text { severe mental illness is } 6 \text { times the general } \\
\text { population }(\mathrm{T})\end{array}$} & $\begin{array}{l}\text { UNCORRECT } \\
\text { RESPONSE }\end{array}$ & 172 & 50.4 & 126 & 50.4 & \multirow{2}{*}{0.00} & \multirow{2}{*}{0.99} \\
\hline & CORRECT RESPONSE & 169 & 49.6 & 124 & 49.6 & & \\
\hline \multirow{2}{*}{$\begin{array}{l}\text { 4. If a person is serious about suicide. there } \\
\text { is little that can be done to prevent it }(\mathrm{F})\end{array}$} & $\begin{array}{c}\text { UNCORRECT } \\
\text { RESPONSE }\end{array}$ & 89 & 26.1 & 77 & 30.8 & \multirow{2}{*}{1.58} & \multirow{2}{*}{0.21} \\
\hline & CORRECT RESPONSE & 252 & 73.9 & 173 & 69.2 & & \\
\hline \multirow{2}{*}{$\begin{array}{l}\text { 5. If you talk to a client about suicide. you } \\
\text { may inadvertently give them permission to } \\
\text { seriously consider it }(\mathrm{F})\end{array}$} & $\begin{array}{c}\text { UNCORRECT } \\
\text { RESPONSE }\end{array}$ & 80 & 23.5 & 59 & 23.6 & \multirow{2}{*}{0.00} & \multirow{2}{*}{0.97} \\
\hline & CORRECT RESPONSE & 261 & 76.5 & 191 & 76.4 & & \\
\hline \multirow[t]{2}{*}{ 6. Depression indicates a suicide risk $(\mathrm{T})$} & $\begin{array}{c}\text { UNCORRECT } \\
\text { RESPONSE }\end{array}$ & 36 & 10.6 & 37 & 14.8 & \multirow{2}{*}{2.40} & \multirow{2}{*}{0.12} \\
\hline & CORRECT RESPONSE & 305 & 89.4 & 213 & 85.2 & & \\
\hline \multirow[t]{2}{*}{ 7. Suicide is always unpredictable $(\mathrm{F})$} & $\begin{array}{c}\text { UNCORRECT } \\
\text { RESPONSE }\end{array}$ & 98 & 28.7 & 78 & 31.2 & \multirow[t]{2}{*}{0.42} & \multirow[t]{2}{*}{0.52} \\
\hline & CORRECT RESPONSE & 243 & 71.3 & 172 & 68.8 & & \\
\hline \multirow[t]{2}{*}{ 8. Suicidal people want to die $(F)$} & $\begin{array}{c}\text { UNCORRECT } \\
\text { RESPONSE }\end{array}$ & 104 & 30.5 & 81 & 32.4 & \multirow[t]{2}{*}{0.24} & \multirow{2}{*}{0.62} \\
\hline & CORRECT RESPONSE & 237 & 69.5 & 169 & 67.6 & & \\
\hline \multirow{2}{*}{$\begin{array}{l}\text { 9. Individuals with Borderline Personality } \\
\text { Disorder frequently discuss or gesture } \\
\text { suicide but do not really intend to kill } \\
\text { themselves; instead, they intend to } \\
\text { provoke or manipulate others (F) }\end{array}$} & $\begin{array}{l}\text { UNCORRECT } \\
\text { RESPONSE }\end{array}$ & 204 & 72.7 & 176 & 70.4 & \multirow[b]{2}{*}{0.36} & \multirow[b]{2}{*}{0.53} \\
\hline & CORRECT RESPONSE & 93 & 27.3 & 74 & 29.6 & & \\
\hline
\end{tabular}


Regarding the impact of a patient's suicide, there were significant differences by profession for 7 of the 18 items (see Table 4). Regarding the impact of a patient's suicide, $28.8 \%$ of physicians, $37.7 \%$ of psychologists, and $41.4 \%$ of nurses reported an increased tendency to hospitalize patients. Approximately $35.8 \%$ of physicians, $49.2 \%$ of psychologists, and $71.9 \%$ of nurses used collegial consultations or peer consultations. Approximately $7.1 \%$ of physicians, $6.9 \%$ of psychologists, and $25.0 \%$ of nurses experienced problems in relationships with friends, while $4.0 \%$ of physicians, $14.0 \%$ of psychologists, and $28.1 \%$ of nurses experienced problems with family. Loss of self-esteem was reported by $13.7 \%$ of physicians, $13.3 \%$ of psychologists, and $28.1 \%$ of nurses. Finally, $8.2 \%$ of physicians, $8.6 \%$ of psychologists, and $25.0 \%$ of nurses experienced emotional numbness (Table 4 ).

Table 4. Impact of a patient suicide on the professional and personal lives of healthcare professionals.

\begin{tabular}{|c|c|c|c|c|c|c|c|c|c|c|c|}
\hline \multirow{2}{*}{ ITEMS } & & \multicolumn{2}{|c|}{ Physician } & \multicolumn{2}{|c|}{ Psychologist } & \multicolumn{2}{|c|}{ Nurse } & \multicolumn{2}{|c|}{ Other } & \multirow{2}{*}{$x^{2}$} & \multirow{2}{*}{$p$} \\
\hline & & $N$ & $\%$ & $N$ & $\%$ & $N$ & $\%$ & $N$ & $\%$ & & \\
\hline \multirow{3}{*}{$\begin{array}{l}\text { 1. Increased attention to legal } \\
\text { aspect of practice }\end{array}$} & DISAGREE & 34 & 31.8 & 20 & 31.3 & 5 & 16.1 & 3 & 18.8 & & \\
\hline & NEITHER & 9 & 8.4 & 4 & 6.3 & 4 & 12.9 & 2 & 12.5 & 4.69 & 0.58 \\
\hline & AGREE & 64 & 59.8 & 40 & 62.5 & 22 & 71.0 & 11 & 68.8 & & \\
\hline \multirow{3}{*}{$\begin{array}{l}\text { 2. Increased tendency to } \\
\text { hospitalize }\end{array}$} & DISAGREE & 55 & 52.9 & 34 & 55.7 & 12 & 41.4 & 3 & 23.1 & & \\
\hline & NEITHER & 19 & 18.3 & 4 & 6.6 & 5 & 17.2 & 1 & 7.7 & 13.01 & 0.04 \\
\hline & AGREE & 30 & 28.8 & 23 & 37.7 & 12 & 41.4 & 9 & 69.2 & & \\
\hline \multirow{3}{*}{$\begin{array}{l}\text { 3. More conservative patient } \\
\text { selection }\end{array}$} & DISAGREE & 75 & 74.3 & 49 & 81.7 & 23 & 74.2 & 11 & 73.3 & & \\
\hline & NEITHER & 10 & 9.9 & 7 & 11.7 & 3 & 9.7 & 0 & 0.0 & 6.38 & 0.38 \\
\hline & AGREE & 16 & 15.8 & 4 & 6.7 & 5 & 16.1 & 4 & 26.7 & & \\
\hline \multirow{3}{*}{ 4. Increased focus on suicide cues } & DISAGREE & 17 & 16.2 & 8 & 12.3 & 2 & 6.1 & 2 & 12.5 & & \\
\hline & NEITHER & 8 & 7.6 & 7 & 10.8 & 0 & 0.0 & 0 & 0.0 & 8.11 & 0.23 \\
\hline & AGREE & 80 & 76.2 & 50 & 76.9 & 31 & 93.9 & 14 & 87.5 & & \\
\hline \multirow{3}{*}{$\begin{array}{l}\text { 5. Increased concerns with death } \\
\text { issues }\end{array}$} & DISAGREE & 21 & 20.2 & 21 & 32.8 & 4 & 12.5 & 3 & 18.8 & & \\
\hline & NEITHER & 18 & 17.3 & 6 & 9.4 & 4 & 12.5 & 4 & 25.0 & 8.83 & 0.18 \\
\hline & AGREE & 65 & 62.5 & 37 & 57.8 & 24 & 75 & 9 & 56.3 & & \\
\hline \multirow{3}{*}{$\begin{array}{l}\text { 6. Increased use of collegial } \\
\text { consultation }\end{array}$} & DISAGREE & 46 & 43.4 & 19 & 30.2 & 7 & 21.9 & 3 & 23.1 & & \\
\hline & NEITHER & 22 & 20.8 & 13 & 20.6 & 2 & 6.3 & 3 & 23.1 & 15.11 & 0.02 \\
\hline & AGREE & 38 & 35.8 & 31 & 49.2 & 23 & 71.9 & 7 & 53.8 & & \\
\hline \multirow{3}{*}{$\begin{array}{l}\text { 7. More conservative record } \\
\text { keeping }\end{array}$} & DISAGREE & 44 & 42.3 & 24 & 38.7 & 8 & 25.8 & 4 & 26.7 & & \\
\hline & NEITHER & 16 & 15.4 & 9 & 14.5 & 3 & 9.7 & 0 & 0.0 & 9.32 & 0.16 \\
\hline & AGREE & 44 & 42.3 & 29 & 46.8 & 20 & 64.5 & 11 & 73.3 & & \\
\hline \multirow{3}{*}{$\begin{array}{l}\text { 8. Increased use of peer } \\
\text { consultation }\end{array}$} & DISAGREE & 41 & 38.3 & 13 & 21.0 & 2 & 6.3 & 4 & 25.0 & & \\
\hline & NEITHER & 19 & 17.8 & 11 & 17.7 & 2 & 6.3 & 2 & 12.5 & 21.89 & 0.00 \\
\hline & AGREE & 47 & 43.9 & 38 & 61.3 & 28 & 87.5 & 10 & 62.5 & & \\
\hline \multirow{3}{*}{$\begin{array}{l}\text { 9. Disturbed relationships with } \\
\text { colleagues }\end{array}$} & DISAGREE & 80 & 80.0 & 50 & 83.3 & 22 & 68.8 & 12 & 80.0 & & \\
\hline & NEITHER & 8 & 8.0 & 3 & 5.0 & 3 & 9.4 & 1 & 6.7 & 3.26 & 0.78 \\
\hline & AGREE & 12 & 12.0 & 7 & 11.7 & 7 & 21.9 & 2 & 13.3 & & \\
\hline \multirow{3}{*}{$\begin{array}{l}\text { 10. Disturbed relationships with } \\
\text { friends }\end{array}$} & DISAGREE & 86 & 86.9 & 54 & 93.1 & 21 & 65.6 & 13 & 86.7 & & \\
\hline & NEITHER & 6 & 6.1 & 0 & 0.0 & 3 & 9.4 & 2 & 13.3 & 18.55 & 0.00 \\
\hline & AGREE & 7 & 7.1 & 4 & 6.9 & 8 & 25.0 & 0 & 0.0 & & \\
\hline \multirow{3}{*}{ 11. Loss of self-esteem } & DISAGREE & 86 & 84.3 & 43 & 71.7 & 20 & 62.5 & 11 & 73.3 & & \\
\hline & NEITHER & 2 & 2.0 & 9 & 15.0 & 3 & 9.4 & 1 & 6.7 & 14.66 & 0.02 \\
\hline & AGREE & 14 & 13.7 & 8 & 13.3 & 9 & 28.1 & 3 & 20.0 & & \\
\hline \multirow{3}{*}{ 12. Dreams related to suicide } & DISAGREE & 82 & 82.8 & 50 & 89.3 & 27 & 87.1 & 15 & 100.0 & & \\
\hline & NEITHER & 6 & 6.1 & 1 & 1.8 & 2 & 6.5 & 0 & 0.0 & 5.00 & 0.54 \\
\hline & AGREE & 11 & 11.1 & 5 & 8.9 & 2 & 6.5 & 0 & 0.0 & & \\
\hline
\end{tabular}


Table 4. Cont.

\begin{tabular}{|c|c|c|c|c|c|c|c|c|c|c|c|}
\hline \multirow{2}{*}{ ITEMS } & & \multicolumn{2}{|c|}{ Physician } & \multicolumn{2}{|c|}{ Psychologist } & \multicolumn{2}{|c|}{ Nurse } & \multicolumn{2}{|c|}{ Other } & \multirow{2}{*}{$x^{2}$} & \multirow{2}{*}{$p$} \\
\hline & & $N$ & $\%$ & $N$ & $\%$ & $N$ & $\%$ & $N$ & $\%$ & & \\
\hline \multirow{3}{*}{$\begin{array}{l}\text { 13. Disturbed relationships with } \\
\text { family }\end{array}$} & DISAGREE & 89 & 89.9 & 48 & 84.2 & 21 & 65.6 & 13 & 86.7 & \multirow{3}{*}{17.15} & \multirow{3}{*}{0.01} \\
\hline & NEITHER & 6 & 6.1 & 1 & 1.8 & 2 & 6.3 & 0 & 0.0 & & \\
\hline & AGREE & 4 & 4.0 & 8 & 14.0 & 9 & 28.1 & 2 & 13.3 & & \\
\hline \multirow{3}{*}{ 14. Intrusive thoughts of suicide } & DISAGREE & 80 & 81.6 & 49 & 83.1 & 21 & 65.6 & 13 & 86.7 & \multirow{3}{*}{7.40} & \multirow{3}{*}{0.29} \\
\hline & NEITHER & 8 & 8.2 & 6 & 10.2 & 4 & 12.5 & 0 & 0.0 & & \\
\hline & AGREE & 10 & 10.2 & 4 & 6.8 & 7 & 21.9 & 2 & 13.3 & & \\
\hline \multirow{3}{*}{ 15. Guilt } & DISAGREE & 63 & 60.0 & 38 & 61.3 & 16 & 50.0 & 9 & 60.0 & \multirow{3}{*}{2.03} & \multirow{3}{*}{0.92} \\
\hline & NEITHER & 15 & 14.3 & 7 & 11.3 & 4 & 12.5 & 2 & 13.3 & & \\
\hline & AGREE & 27 & 25.7 & 17 & 27.4 & 12 & 37.5 & 4 & 26.7 & & \\
\hline \multirow{3}{*}{ 16. Anger } & DISAGREE & 59 & 57.8 & 28 & 44.4 & 14 & 43.8 & 8 & 50.0 & \multirow{3}{*}{5.06} & \multirow{3}{*}{0.54} \\
\hline & NEITHER & 13 & 12.7 & 10 & 15.9 & 3 & 9.4 & 2 & 12.5 & & \\
\hline & AGREE & 30 & 29.4 & 25 & 39.7 & 15 & 46.9 & 6 & 37.5 & & \\
\hline \multirow{3}{*}{ 17. Emotional numbness } & DISAGREE & 87 & 88.8 & 50 & 86.2 & 19 & 59.4 & 13 & 86.7 & \multirow{3}{*}{17.18} & \multirow{3}{*}{0.01} \\
\hline & NEITHER & 3 & 3.1 & 3 & 5.2 & 5 & 15.6 & 0 & 0.0 & & \\
\hline & AGREE & 8 & 8.2 & 5 & 8.6 & 8 & 25.0 & 2 & 13.3 & & \\
\hline \multirow{3}{*}{ 18. Social withdrawal } & DISAGREE & 90 & 91.8 & 51 & 85.0 & 24 & 75.0 & 13 & 86.7 & \multirow{3}{*}{6.91} & \multirow{3}{*}{0.33} \\
\hline & NEITHER & 2 & 2.0 & 2 & 3.3 & 2 & 6.3 & 0 & 0.0 & & \\
\hline & AGREE & 98 & 6.1 & 60 & 11.7 & 32 & 18.8 & 15 & 13.3 & & \\
\hline
\end{tabular}

\section{Discussion}

The principal aim of the present study was to assess self-reported attitudes and knowledge about suicide in a large sample of mental health professionals. For this purpose, we examined the relationship between the Suicide Knowledge and Skills Questionnaire items and the experience of a patient's suicide. In addition, we also examined the association between items of the Impact of a Patient's Suicide on Professional and Personal Lives Scale and different healthcare professions.

We found a significant relationship between the experience of a patient's suicide and items on the SKSQ. A large proportion of the participants did not feel that they had the training or skills to help suicidal patients, and $60 \%$ of the total sample did not feel that they had the support and supervision needed to engage with and assist those with suicidal desires. However, the results indicated that healthcare professionals who had experienced a patient suicide reported greater skills than professionals who had not experienced a patient suicide. Feeling comfortable asking about suicide was still significant in multivariate analysis while controlling for years of professional experience. These findings can be explained by the fact that healthcare professionals usually receive more training in suicide prevention after a patient suicide. Several psychiatric services offer psychological support after a patient's suicide, and healthcare professionals who had experienced a patient's suicide learned from that experience how to better manage suicide risk [26,27]. Healthcare professionals who had experienced a patient's suicide reported administering improved suicide risk assessments, felt better able to ask patients questions about suicidal ideation, and were more aware of suicide risk factors [28].

Previous studies have shown that healthcare professionals who worked with suicidal patients had reported a better knowledge of suicide and were more likely to receive suiciderelated training $[29,30]$. Thus, experiencing a patient suicide may prompt healthcare professionals to seek further training, and this training may increase the willingness of healthcare professionals to treat patients at risk of suicide [23].

However, we did not find a significant difference for the item "I have the support/supervision I need to engage and assist those with suicidal desire" between professionals who had experienced a patient suicide and those who had not. Both groups felt that they did not have the necessary support to manage suicidal patients. In particular, 
$44 \%$ of professionals who experienced a patient suicide felt that they did not have the proper training on this particular issue. Our results support previous papers that have demonstrated that only a small percentage of healthcare professionals consider themselves sufficiently trained to work with patients at risk of suicide [31,32]. In a study by Samuelsson et al. [33] on 191 psychiatric nurses, only 25\% considered themselves sufficiently trained for this work. In another study with a sample of 300 psychiatric staff, only $44.3 \%$ considered themselves sufficiently trained [31].

Finally, we examined the association between the Impact of a Patient's Suicide on Professional and Personal Lives Scale and the different healthcare professions. The results showed a significant relationship between the profession and "increased tendency to hospitalize," "increased use of collegial consultation", "increased use of peer consultation", "disturbed relationships with friends", "loss of self-esteem", "disturbed relationships with family", "emotional numbness", with nurses reporting the more negative impact than did psychiatrists and psychologists. Compared to other professional figures, the more negative impact reported by nurses might be explained by their broad education background, not necessarily involving mental health issues and perspectives. Overall, our results show that improved knowledge and improved attitudes toward suicide are important factors for suicide-prevention strategies.

A study conducted by Takahashi et al. [34], in fact, has analyzed the exposure to patients' suicide and the consequences on nurses in terms of stress. The results have shown that the absence of formal systems to deal with the psychological aftermaths of such an event causes significant distress and a higher burden on nurses.

Moreover, after a patient suicide, there was an increased tendency to hospitalize patients with suicide risk and an increased use of collegial consultation. Concerning personal emotions, healthcare professionals reported troubled relationships with family and friends and a loss of self-esteem, confirming the personal and professional consequences of a patient's suicide on healthcare professionals [35].

This study had several limitations. First, the healthcare professionals involved in the study belonged to different professional groups. Some groups interviewed had a small sample size. Second, the participants attended a symposium on suicide and may not represent all healthcare professionals. Finally, the perception of being sufficiently trained is not an objective measure since individuals may misjudge their competence.

\section{Conclusions}

In conclusion, this study investigated an issue of public health interest: the preparation of healthcare professionals for assessing and treating suicidal patients. Our results highlight the emotional and professional impact that a patient suicide can have on healthcare professionals. Our results demonstrated that a large proportion of the participants did not feel that they had the training or skills to help suicidal patients. Overall, our results show that increased knowledge and improved attitudes about suicide are important factors for suicide-prevention strategies. As suggested in previous studies, developing suicide-prevention campaigns and training seems essential for increasing the knowledge of healthcare professionals about suicide and people at risk of suicide, their family members, and people bereaved by suicide [36,37]. Furthermore, offering programs and training on suicide are important for other professionals, including school personnel, researchers, and policymakers, to improve prevention strategies to reduce suicide risk [1].

Author Contributions: Conceptualization, M.P., D.E. and I.B.; methodology, M.P., M.I. and S.S.; software, M.I.; formal analysis, M.I. and S.S.; investigation, I.B., E.R., G.N. and D.E.; data curation, E.R. and A.S.; writing—original draft preparation, D.E. and I.B.; writing—review and editing, D.L.; M.P. All authors have read and agreed to the published version of the manuscript.

Funding: This research received no external funding. 
Institutional Review Board Statement: The study was conducted according to the guidelines of the Declaration of Helsinki. and approved by Department of Neurosciences, Mental Health and Sensory Organs.

Informed Consent Statement: The survey was anonymous, by returning the form participants accepted to take part in the study.

Data Availability Statement: The datasets used and/or analyzed during the current study are available from the corresponding author on reasonable request.

Conflicts of Interest: The authors declare no conflict of interest.

\section{References}

1. Lamis, D.A.; Underwood, M.; D'Amore, N. Outcomes of a suicide prevention gatekeeper training program among school personnel. Crisis 2017, 38, 89-99. [CrossRef]

2. Health Service Executive, the National Suicide Review Group. Department of Health and Children Reach Out: National Strategy for Action on Suicide Prevention 2005-2014; Health Service Executive: Dublin, Island, 2005.

3. Abbey, K.J.; Madsen, C.H., Jr.; Polland, R. Short-term suicide awareness curriculum. Suicide Life Threat. Behav. 1989, 19, $216-227$. [CrossRef] [PubMed]

4. Aseltine, R.H., Jr.; DeMartino, R. An outcome evaluation of the SOS Suicide Prevention Program. Am. J. Public Health 2004, 94, 446-451. [CrossRef] [PubMed]

5. Bean, G.; Baber, K.M. Connect: An effective community-based youth suicide prevention program. Suicide Life Threat. Behav. 2011, 41, 87-97. [CrossRef] [PubMed]

6. Tompkins, T.L.; Witt, J.; Abraibesh, N. Does a gatekeeper suicide prevention program work in a school setting? Evaluating training outcome and moderators of effectiveness. Suicide Life Threat. Behav. 2010, 40, 506-515. [CrossRef]

7. Dexter-Mazza, E.T.; Freeman, K.A. Graduate training and the treatment of suicidal clients: The students' perspective. Suicide Life Threat. Behav. 2003, 33, 211-218. [CrossRef]

8. Pisani, A.R.; Cross, W.F.; Gould, M.S. The assessment and management of suicide risk: State of workshop education. Suicide Life Threat. Behav. 2011, 41, 255-276. [CrossRef]

9. Schmitz, W.M., Jr.; Allen, M.H.; Feldman, B.N.; Gutin, N.J.; Jahn, D.R.; Kleespies, P.M.; Quinnett, P.; Simpson, S. Preventing suicide through improved training in suicide risk assessment and care: An American Association of Suicidology Task Force report addressing serious gaps in U.S. mental health training. Suicide Life Threat. Behav. 2012, 42, 292-304. [CrossRef]

10. Hooper, L.M.; Epstein, S.A.; Weinfurt, K.P.; DeCoster, J.; Qu, L.; Hannah, N.J. Predictors of primary care physicians' self-reported intention to conduct suicide risk assessments. J. Behav. Health Serv. Res. 2012, 39, 103-115. [CrossRef]

11. Stene-Larsen, K.; Reneflot, A. Contact with primary and mental health care prior to suicide: A systematic review of the literature from 2000 to 2017. Scand. J. Public Health 2019, 47, 9-17. [CrossRef]

12. Mann, J.J.; Apter, A.; Bertolote, J.; Beautrais, A.; Currier, D.; Haas, A.; Hegerl, U.; Lonnqvist, J.; Malone, K.; Marusic, A.; et al. Suicide prevention strategies: A systematic review. JAMA 2005, 294, 2064-2074. [CrossRef]

13. Burnette, C.; Ramchand, R.; Ayer, L. Gatekeeper Training for Suicide Prevention: A Theoretical Model and Review of the Empirical Literature. Rand Health $Q$ 2015, 5, 1.

14. Osteen, P.J.; Frey, J.J.; Ko, J. Advancing training to identify, intervene, and follow up with individuals at risk for suicide through research. Am. J. Prev. Med. 2014, 47 (Suppl. 2), S216-S221. [CrossRef]

15. O'Connor, R.C.; Smyth, R.; Ferguson, E.; Ryan, C.; Williams, J.M. Psychological processes and repeat suicidal behavior: A four-year prospective study. J. Consult. Clin. Psychol. 2013, 81, 1137-1143. [CrossRef] [PubMed]

16. Castelli Dransart, D.A.; Heeb, J.L.; Gulfi, A.; Gutjahr, E.M. Stress reactions after a patient suicide and their relations to the profile of mental health professionals. BMC Psychiatry 2015, 15, 265. [CrossRef] [PubMed]

17. Castelli Dransart, D.A.; Gutjahr, E.; Gulfi, A.; Didisheim, N.K.; Seguin, M. Patient suicide in institutions: Emotional responses and traumatic impact on Swiss mental health professionals. Death Stud. 2014, 38, 315-321. [CrossRef]

18. Saunders, K.E.; Hawton, K.; Fortune, S.; Farrell, S. Attitudes and knowledge of clinical staff regarding people who self-harm: A systematic review. J. Affect. Disord. 2012, 139, 205-216. [CrossRef]

19. Castelli Dransart, D.A.; Treven, M.; Grad, O.T.; Andriessen, K. Impact of client suicide on health and mental health professionals. In Postvention in Action: The International Handbook of Suicide Bereavement Support; Andriessen, K., Krysinska, K., Grad, O.T., Eds.; Hogrefe Publishing: Boston, MA, USA, 2017; pp. 245-254.

20. Pompili, M.; Girardi, P. Emergency staff reactions to suicidal and self-harming patients. Eur. J. Emerg. Med. 2005, 12, 169-178. [CrossRef]

21. Gaynes, B.N.; West, S.L.; Ford, C.A.; Frame, P.; Klein, J.; Lohr, K.N. US Preventive Services Task Force. Screening for suicide risk in adults: A summary of the evidence for the U.S. Preventive Services Task Force. Ann. Intern. Med. 2004, 140, 822-835. [CrossRef]

22. Smith, A.R.; Silva, C.; Covington, D.W.; Joiner, T.E. An assessment of suicide-related knowledge and skills among health professionals. Health Psychol. 2014, 33, 110-119. [CrossRef] [PubMed] 
23. Silva, C.; Smith, A.R.; Dodd, D.R.; Covington, D.W.; Joiner, T.E. Suicide-Related Knowledge and Confidence Among Behavioral Health Care Staff in Seven States. Psychiatr. Serv. 2016, 67, 1240-1245. [CrossRef] [PubMed]

24. Chemtob, C.M.; Hamada, R.S.; Bauer, G.; Torigoe, R.Y.; Kinney, B. Patient suicide: Frequency and impact on psychologists. Prof. Psychol. Res. Pract. 1988, 19, 416. [CrossRef]

25. Chemtob, C.M.; Hamada, R.S.; Bauer, G.; Kinney, B.; Torigoe, R.Y. Patients' suicides: Frequency and impact on psychiatrists. Am. J. Psychiatry 1988, 145, 224-228. [PubMed]

26. Pompili, M.; Erbuto, D.; Innamorati, M.; Migliorati, M.; Girardi, P. Assessment of suicide-related knowledge and skills in a sample of health professionals and students. Eur. Psychiatry 2017, 41, 300-301. [CrossRef]

27. Courtney, K.P.; Stephens, I.P. The experience of patients' suicide among trainees in psychiatry. Psychiat. Bull. 2001, $25,51-52$. [CrossRef]

28. Rytterstrom, P.; Ovox, S.M.; Wardig, R.; Hultsjo, S. Impact of suicide on health professionals in psychiatric care mental healthcare professionals' perceptions of suicide during ongoing psychiatric care and its impact s on their continued care work. Int. J. Ment. Health Nurs. 2020, 29, 982-991. [CrossRef]

29. Grad, O.T.; Zavasnik, A.; Groleger, U. Suicide of a patient: Gender differences in bereavement reactions of therapists. Suicide Life Threat. Behav. 1997, 27, 379-386. [PubMed]

30. Hendin, H.; Haas, A.P.; Maltsberger, J.T.; Szanto, K.; Rabinowicz, H. Factors contributing to therapists' distress after the suicide of a patient. Am. J. Psychiatry 2004, 161, 1442-1446. [CrossRef]

31. Ramberg, I.L.; Wasserman, D. Benefits of implementing an academic training of trainers program to promote knowledge and clarity in work with psychiatric suicidal patients. Arch Suicide Res. 2004, 8, 331-343. [CrossRef] [PubMed]

32. Ramberg, I.L.; Di Lucca, M.A.; Hadlaczky, G. The Impact of Knowledge of Suicide Prevention and Work Experience among Clinical Staff on Attitudes towards Working with Suicidal Patients and Suicide Prevention. Int. J. Environ. Res. Public Health 2016, 13, 195. [CrossRef]

33. Samuelsson, M.; Asberg, M.; Gustavsson, J.P. Attitudes of psychiatric nursing personnel towards patients who have attempted suicide. Acta Psychiatr. Scand. 1997, 95, 222-230. [CrossRef] [PubMed]

34. Takahashi, C.; Chida, F.; Nakamura, H.; Akasaka, H.; Yagi, J.; Koeda, A.; Takusari, E.; Otsuka, K.; Sakai, A. The impact of inpatient suicide on psychiatric nurses and their need for support. BMC Psychiatry 2011, 8, 11-38. [CrossRef] [PubMed]

35. Tillman, J.G. When a patient commits suicide: An empirical study of psychoanalytic clinicians. Int. J. Psychoanal. 2006, 87, 159-177. [CrossRef] [PubMed]

36. Chambers, D.A.; Pearson, J.L.; Lubell, K.; Brandon, S.; O’Brien, K.; Zinn, J. The science of public messages for suicide prevention: A workshop summary. Suicide Life Threat. Behav. 2005, 35, 134-145. [CrossRef]

37. Ftanou, M.; Skehan, J.; Krysinska, K.; Bryant, M.; Spittal, M.J.; Pirkis, J. Crafting safe and effective suicide prevention media messages: Outcomes from a workshop in Australia. Int. J. Ment. Health Syst. 2018, 12, 23. [CrossRef] [PubMed] 